\title{
Biometric relationships in the red sea pen Pennatula rubra (Cnidaria: Pennatulacea)
}

\author{
Giovanni Chimienti \\ Dept. of Biology and CoNISMa LRU \\ University of Bari Aldo Moro \\ Bari, Italy \\ giovanni.chimienti@uniba.it
}

\author{
Angelo Tursi \\ Dept. of Biology and CoNISMa LRU \\ University of Bari Aldo Moro \\ Bari, Italy \\ angelo.tursi@uniba.it
}

\author{
Francesco Mastrototaro \\ Dept. of Biology and CoNISMa LRU \\ University of Bari Aldo Moro \\ Bari, Italy \\ francesco.mastrototaro@uniba.it
}

\begin{abstract}
Colonies of the red sea pen Pennatula rubra sampled by trawling in the northwestern Mediterranean Sea were analyzed. Biometric parameters such as total length, rachis length, number of polyp leaves, wet weight and dry weight were measured and related to each other by means of regression analysis. The most reliable measures for future inferencing of colonies size and biomass through visual techniques were individuated in order to allow a noninvasive study of $\mathrm{P}$. rubra population structure and dynamics.
\end{abstract}

Keywords - Corals, correlation, measures, biometry, Mediterranean

\section{INTRODUCTION}

In the era of genomics and molecular zoology, looking at animal body and measure it to find proper biometric correlations can still reveal useful information for scientific purposes. Morphological studies have historically been the fundament of zoological knowledge, allowing the currently used taxonomic descriptions, as well as the understanding of species biology and evolution. However, many relationships between different anatomical parts are still to be understood for most of the animal species, especially for invertebrates. This is particularly urgent for fragile marine species with a peculiar aggregative behavior that contribute to create biogenic habitats, such as coral frameworks and forests $[1,2$, 3], particularly on soft bottoms [4]. Among them, sea pens are important field-forming octocorals, providing relevant structure in flat, low-relief soft-bottom habitats where there is little physical habitat complexity. These fields create an essential biogenic habitat for suprabenthic and benthic invertebrates, as well as an important feeding and nursery area for a rich demersal fish fauna $[5,6,7,8,9]$. Pennatulacean fields are usually difficult to be found because the habitat mapping geophysical techniques are not able to detect them. The only possible way to identify these fields on a large scale still remains trawling, through the analysis of commercial fishing bycatch data and/or experimental trawl fishing surveys data. Despite their importance in benthic ecology, little is still known about sea pen biology and ecology, and their vulnerability to human pressures has been assessed under a precautionary approach [9]. Destructive sampling is still needed to collect information about colonies size and their main features. However, the finding of proper biometric correlations could avoid the need of further sampling for the study of these populations in the near future. Underwater imagery techniques, such as remotely operated vehicles (ROVs) and towed cameras, are now allowing a better understanding of the sea pen numerical importance, in order to validate their modelled distributions and to establish in situ monitoring [10], representing a valid alternative to destructive sampling. Moreover, visual techniques provide further evidences of the ecological importance of sea pen fields as nursery area and refuge for many associated species $[5,8]$.

The present study reports some morphometric relationships found in a population of the red sea pen Pennatula rubra (Ellis, 1761), one of the most important field-forming sea pens of the Mediterranean continental shelf $[11,12]$. These correlations would greatly enhance the value of ROV imaging by enabling future in situ estimations of sea pen size and biomass, in order to understand the population structure and the ecological role that such fields play in marine ecosystems $[12,13]$. In particular, the relationships between the visible portions of the sea pens (above the peduncle) and the total length are needed, as imagery is unable to capture the total length [9]. The finding of reliable biometric relationships would avoid the need of sampling for the study of $P$. rubra population structure and dynamic, representing a necessary knowledge base for a noninvasive study of the wild populations of this sea pen.

\section{MATERIALS AND METHODS}

Colonies of $P$. rubra were sampled using an experimental trawl net with a stretched mesh of $20 \mathrm{~mm}$ in the codend, in the frame of the MEDITS (MEDiterranean International bottom Trawl Survey) project [14]. Sampling was carried out during 2013 northwest Punta Alice (Ionian Sea, southern Italy; Fig. 1) [11, 12], onboard the Pasquale e Cristina

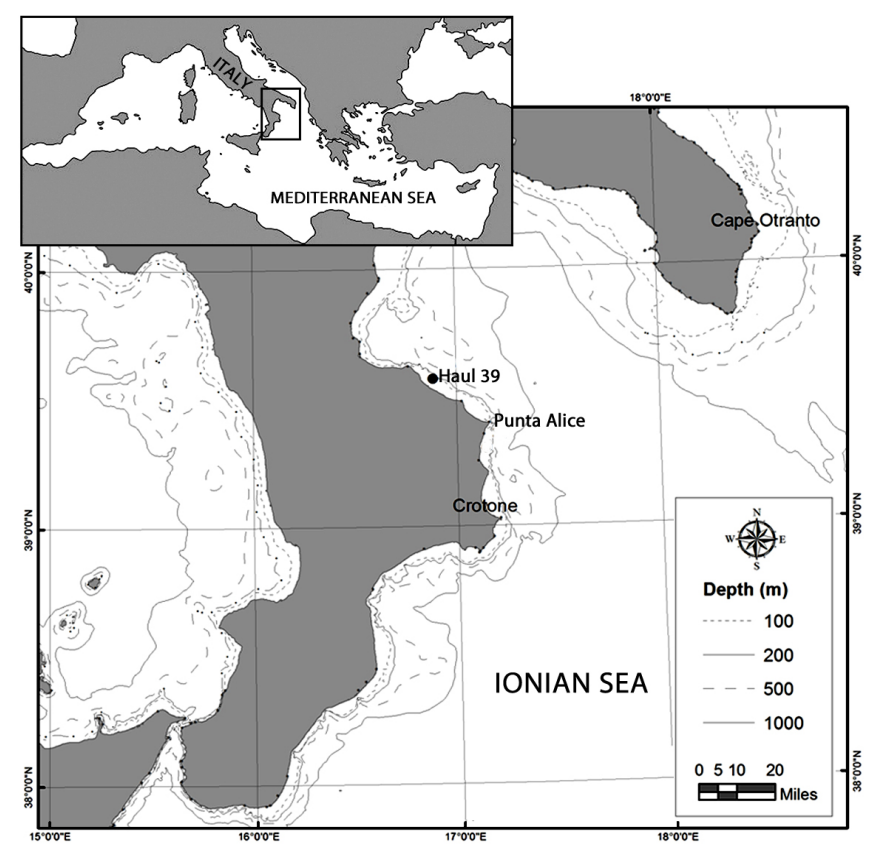

Fig. 1. Study area and location of the haul 39 (black spot), northwest Punta Alice (Southern Italy, Ionian Sea), where the colonies of Pennatula rubra were sampled. 
fishing vessel. The catches from the haul 39 (Start: $39^{\circ} 35.05^{\prime} \mathrm{N}-16^{\circ} 52.26^{\prime} \mathrm{E}$; End: $39^{\circ} 34.05^{\prime} \mathrm{N}-16^{\circ} 53.63^{\prime} \mathrm{E}$; 61-65 $\mathrm{m}$ depth) were considered in this study. A SCANMAR acoustic system [15] was used to measure the horizontal and vertical openings of the net in order to estimate the swept area. The colonies of $P$. rubra sampled were preserved on board at $-20^{\circ} \mathrm{C}$.

A total of 168 colonies, sampled over an area of 40,996 $\mathrm{m}^{2}$, were analyzed. The following biometric parameters were measured for each colony: length of the rachis $(\mathrm{mm})$, total length of the colony (considering both rachis and peduncle; $\mathrm{mm}$ ), wet weight (g), and number of polyp leaves (Fig. 2). In particular, both right and left polyp leaves of each colony were counted, and the mean value was calculated when the number was different from the two sides of the same colony. Measurements were carried out in laboratory after thawing, considering that the freezing process causes the complete contraction of the colonies. On the contrary, living colonies can contain a highly variable quantity of seawater driving their contraction and considerably changing their size and wet weight [12].

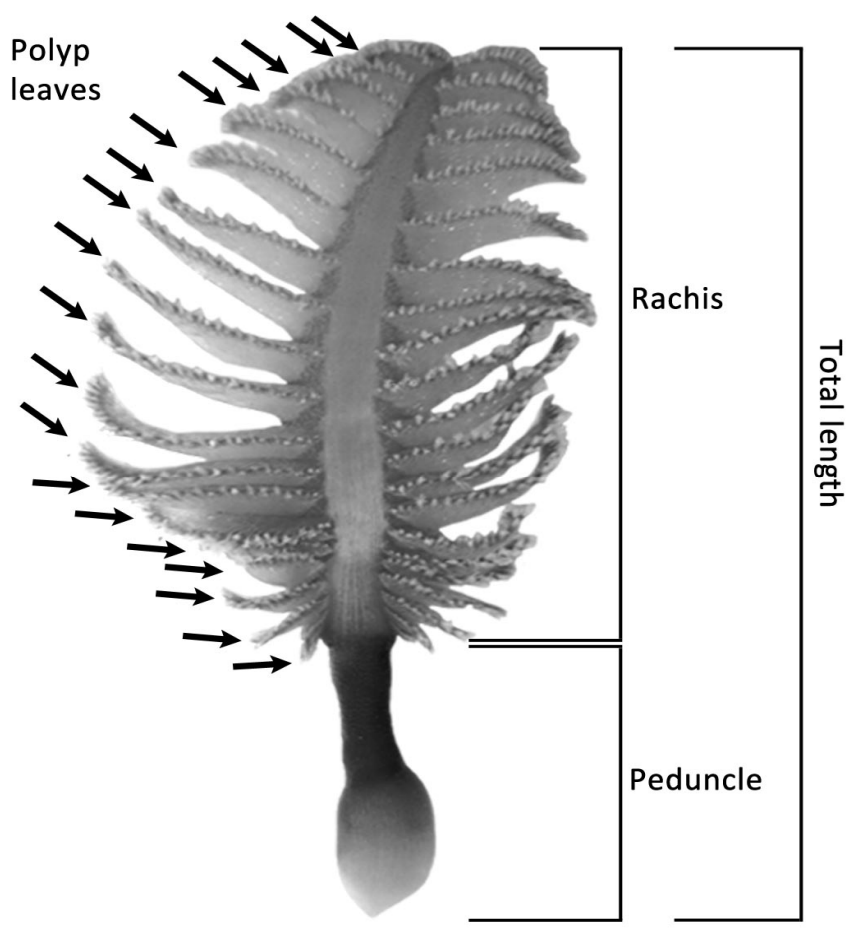

Fig. 2. Polyp leaves (black arrows), rachis, peduncle and total length in a colony of Pennatula rubra.

Dry weight (g) was also measured for each colony after drying in an oven at $40^{\circ} \mathrm{C}$ for 96 hours. The relationship among all the biometric parameters was computed by means of regression analysis.

\section{RESULTS}

All the biometric correlations found in P. rubra showed significant exponential relationships, with $\mathrm{P}<0.01$ for all of them and $\mathrm{P}<0.001$ between dry and wet weight, and between rachis and total length. In particular, the dry weight resulted highly correlated with the wet weight $\left(\mathrm{R}^{2}=0.89\right.$; Fig. 3a) and with the number of polyp leaves $\left(\mathrm{R}^{2}=0.82\right.$; Fig. $3 b)$, while less correlated with the total length $\left(R^{2}=0.78\right.$;
Fig. 3c) and with the rachis length $\left(\mathrm{R}^{2}=0.79\right.$; Fig. $\left.3 \mathrm{~d}\right)$. This highlighted how the water content can affect length measurements due to a different contraction of the colony, while wet weight and number of polyp leaves can be considered better proxies for the dry weight estimation. The rachis length and the total length measurements showed similar relationships with both wet and dry weight measurements (Fig. 3e; Fig. 3g).

The $\mathrm{R}^{2}$ of the regression between the total length and the rachis length was close to 1 , with a very strong correlation between these two length measurements $\left(R^{2}=0.98\right.$; Fig. $\left.3 f\right)$. The total length was also well correlated with the number of polyp leaves $\left(\mathrm{R}^{2}=0.77\right.$; Fig. $\left.3 \mathrm{~h}\right)$, suggesting the latter as a measure for total length inference when colonies' contraction level is not at the minimum (e.g., living colonies). The number of polyp leaves was strongly correlated with both wet and dry weight values (Fig. 3b; Fig. 3j), and with both rachis and total length measurements (Fig. 3h; Fig. 3i), proving to be a reliable proxy to estimate both length and weight in $P$. rubra colonies through ROV imaging, allowing to bypass the bias of colonies contraction and water content.

\section{DISCUSSION}

With the progress in fishing gear technology, trawling has nowadays a heavy devastating mechanical impact on soft bottom habitats [16]. Aggregations of sea pens, as Funiculina quadrangularis (Pallas, 1766), and of alcyonaceans, as Isidella elongata (Esper, 1788), almost completely disappeared from most of the trawlable bottoms of the Mediterranean Sea [4, 16, 17, 18, 19], despite being very common in the past $[20,21]$. For this reason, anthozoans forests and fields still present on soft bottoms are of primary importance for conservation purposes and worthy of urgent protection [3], representing true Vulnerable Marine Ecosystems [2, 22, 23]. This is true also for extensive populations of the Mediterranean endemic sea pen P. rubra, whose geographic and bathymetric distribution within the basin is still not yet exhaustively known. This species has been reported as vulnerable in the last update of the IUCN Red List [24], among the seventeen threatened coral species of the Mediterranean Sea. Considering that P. rubra populations develop on trawlable grounds, and that colonies show slow time of withdrawal and large surface of exposure [12], this species is considered highly threatened by destructive fishing practices. In fact, despite the trawling catch efficiency of $P$. rubra is low overall [13], incidental mortality can be very high due to physical damages such as dislodgement, fracture of the axial rod and soft tissue abrasion $[13,25,26]$.

The biometric measures on P. rubra revealed useful correlations among different portion of the colonies (e.g. rachis, total length, number of polyp leaves), as well as between size and biomass. In particular, both dry and wet weight showed the strongest correlation with the number of polyp leaves. This would allow the inference of $P$. rubra biomass from ROV imaging, considering that colonies observed in vivo are extended enough to allow the observation and the count of polyp leaves at least at one colony side [12] (Fig. 4). Moreover, the dry weight of sampled colonies could be inferred by the more rapid measurement of the wet weight thanks to the reliable correlation found here, applicable only on contracted colonies (e.g., after freezing). This would help to rapidly 

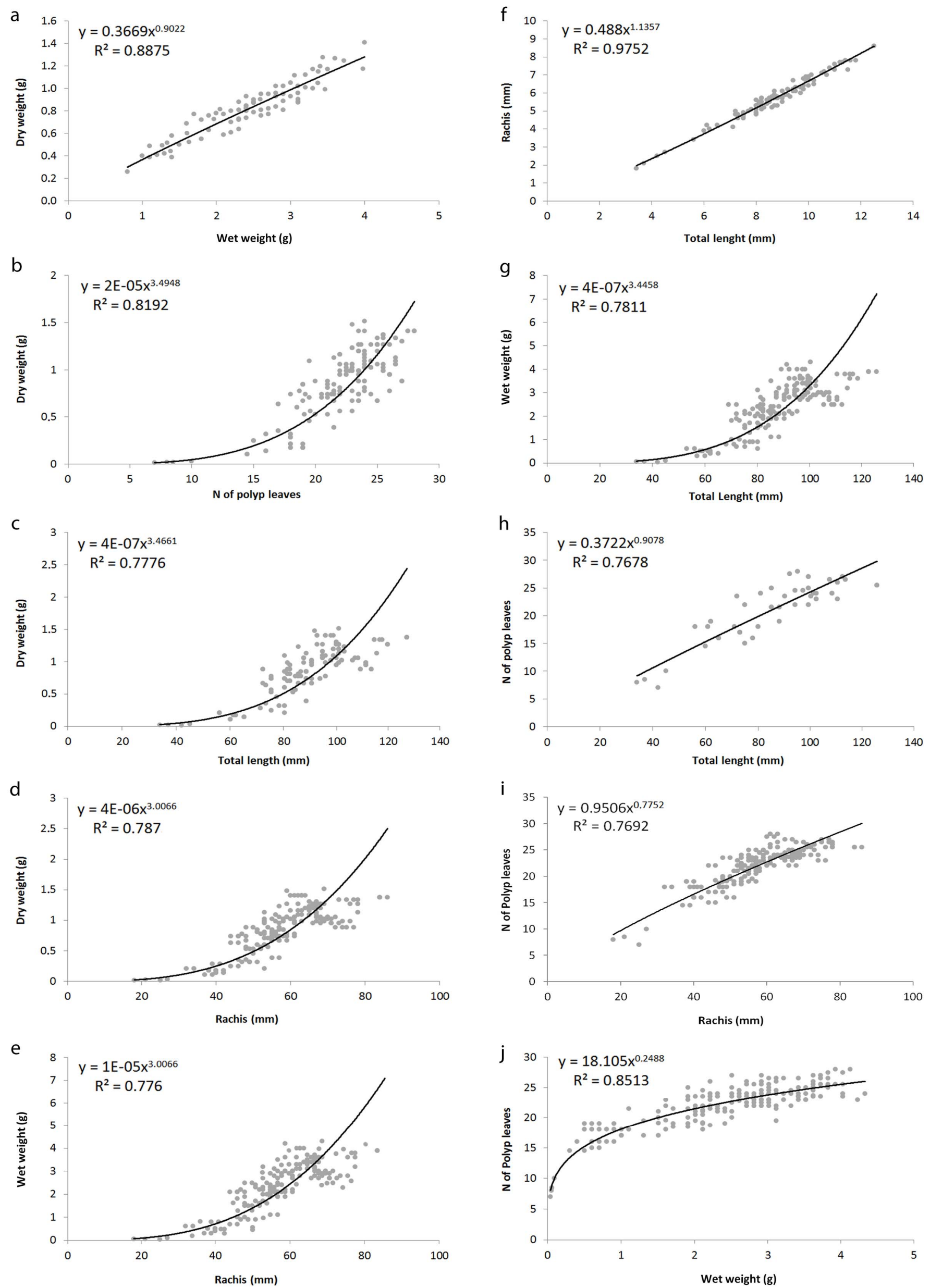

Fig. 3. Biometric relationships of the sampled colonies of Pennatula rubra. 
understand the dry biomass of a sea pen field (e.g., onboard a fishing vessel) without the need of drying procedures.

Considering that the peduncle of living colonies is under the sediments and the rachis is the only visible portion (Fig. 4 ), the total length can be estimated in vivo from the number of polyp leaves. Despite a very clear relationship between total length and rachis length was here confirmed, accordingly to what observed for other pennatulid species [9], rachis length in living colonies of $P$. rubra can vary due to the different water content, thus it is not recommended as a proxy for total length indirect measures by using ROV. For this reason, the number of polyp leaves resulted the preferred measure also for the estimation of colonies size from imaging data.

The experimental trawl fishing projects mainly targeting the assessment of demersal resources [14] can provide useful information to identify sea pen fields [13]. However, despite trawling often being used in soft-bottom benthic community studies, nondestructive monitoring with visual techniques (e.g., ROV) is extensively recommended for the study of sea pen fields in order to support protection and management strategies. Once found reliable biometric correlations, the use
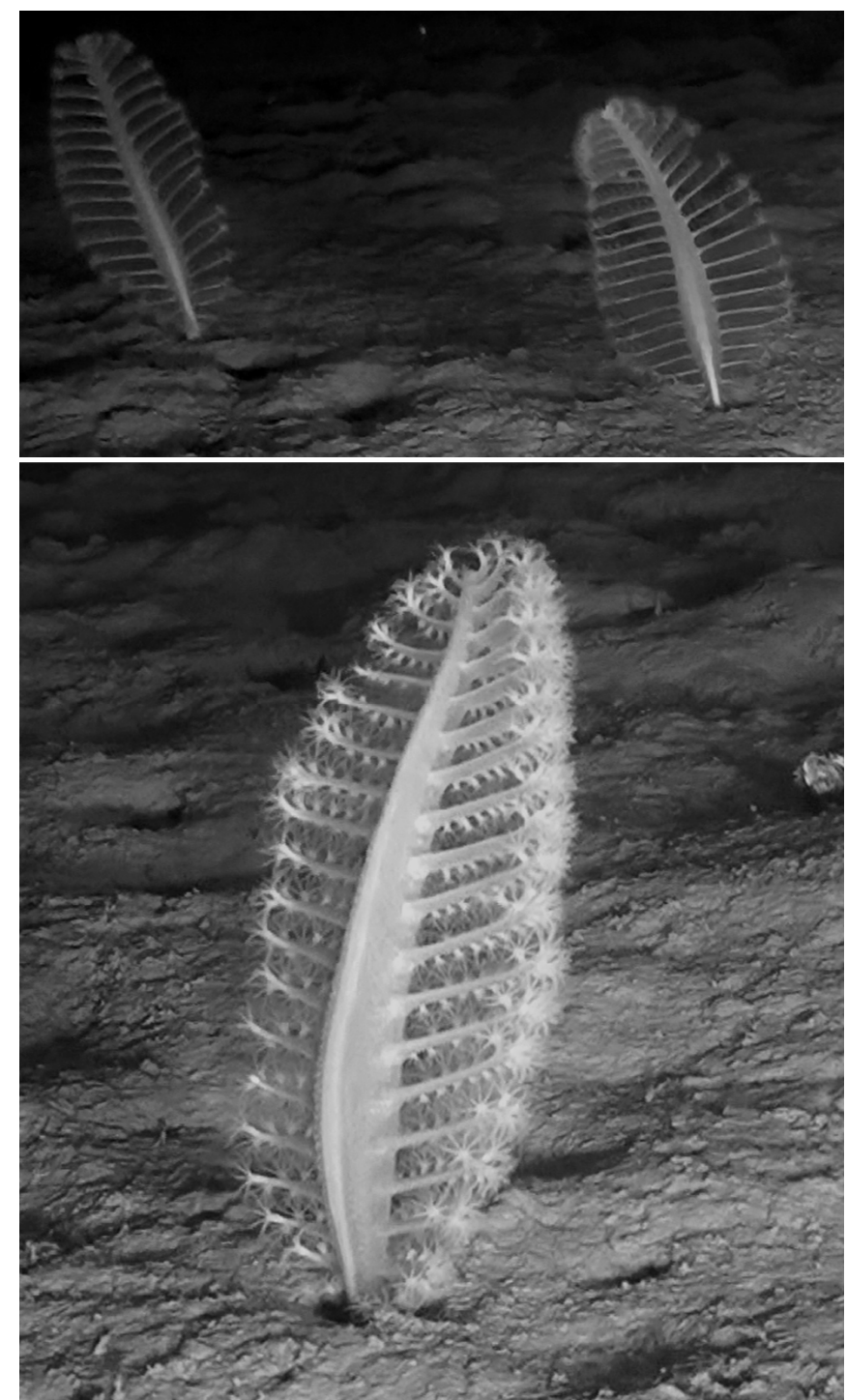

Fig. 4. Examples of Pennatula rubra colonies observed with the ROV in their natural environment. of visual techniques would allow indirect and noninvasive measures to assess the population structure, and to monitor its dynamic through time without affecting the population studied.

This study provides biometric tools for the future monitoring of the populations of $P$. rubra in the northwestern Mediterranean Sea, without the need of further sampling for biomass and size-frequency estimates aiming the study of population structure and dynamic. Future perspectives include the finding of similar correlations in other species of sea pens sampled for other purposes, as for the facies of Kophobelemnon stelliferum (Müller, 1776) found in the Ionian Sea [18]. On the contrary, this approach cannot be applied to rare species such as the endemic sea pen Crassophyllum thessalonicae Vafidis \& Koukouras, 1991, only known from the Thermaikos Gulf (Greece) [27] and the wip-like sea pen Protoptilum carpenteri Kölliker, 1872, found only in two areas of the Mediterranean Sea [4, 28]. The identification of proper biometric relationships has been recently carried out for other sea pen species in eastern Canada [9], and is common for size-frequency distribution of other octocorals [29], as well as for other marine invertebrates [30]. Exponential length-weight relationship for P. rubra is in accordance with those found for the congeneric Pennatula aculeata Danielssen, 1860 and Pennatula grandis Ehrenberg, 1834 in the Canadian waters[9]. However, length and biomass can slightly vary within different populations of the same species, depending on environmental conditions and food availability, as observed for other sea pens in the North Atlantic [9]. For this reason, data from different populations of $P$. rubra within the Mediterranean Sea would help to refine the biometric relationships here found, in order to make them applicable on a basin scale and to highlight potential morphometric differences among populations.

\section{ACKNOWLEDGMENT}

We thank crew and Capitan of the fishing vessel Pasquale e Cristina for their support during the operations at sea. This study was performed under the Data Collection Framework, cofounded by the EU and the Italian Ministry of Agriculture, Food and Forestry Policies (MIPAAF).

\section{REFERENCES}

[1] G. Chimienti, M. Bo and F. Mastrototaro, "Know the distribution to assess the changes: Mediterranean cold-water coral bioconstructions," Rend. Lincei Sci. Fis. Nat., vol. 29, pp. 583-588, 2018.

[2] G. Chimienti, M. Bo, M. Taviani and F. Mastrototaro, "Occurrence and biogeography of Mediterranean cold-water corals," in: Mediterranean Cold-Water Corals: Past, Present and Future, Springer (in press), C. Orejas and C. Jiménez Eds., 2018.

[3] S. Rossi, L. Bramanti, A. Gori and C. Orejas, "An overview of the animal forests of the world," in: Marine animal forests, S. Rossi, Ed. The Netherlands: Springer International Publishing AG, 2017, pp. 126.

[4] F. Mastrototaro, G. Chimienti, J. Acosta, J. Blanco, S. Garcia, J. rivera and R. Aguilar, "Isidella elongata (Cnidaria: Alcyonacea) facies in the western Mediterranean Sea: visual surveys and descriptions of its ecological role," Eur. Zool. J., vol. 84(1), pp. 209225, 2017.

[5] E. M. D. Porporato, F. De Domenico, M. C. Mangano and N. Spanò, "Macropodia longirostris and Latreillia elegans (Decapoda, Brachyura) climbing on Mediterranean Pennatulidae (Anthozoa, Octocorallia): a preliminary note," Crustaceana, vol. 84, pp. 1777$1780,2011$. 
[6] S. Baillon, J. F. Hamel, V. E. Wareham and A. Mercier, "Deep coldwater corals as nurseries for fish larvae," Front. Ecol. Environ., vol. 10, pp. 351-256, 2012.

[7] E. Kenchington, F. J. Murillo, C. Lirette, M. Sacau, M. Koen-Alonso, A. Kenny, N. Ollerhead, V. Wareham and L. Beazley, "Kernel Density Surface Modelling as a Means to Identify Significant Concentrations of Vulnerable Marine Ecosystem Indicators," PLoS ONE, vol. 9(10), pp. e109365, 2014.

[8] S. Ruiz-Pico, A. Serrano, A. Punzón, A. Altuna, O. Fernández-Zapico and F. Velasco, "Sea pen (Pennatulacea) aggregations on the northern Spanish shelf: distribution and faunal assemblages," Sci. Mar., vol. 81(3), pp. 1-11, 2017.

[9] F. J. Murillo, B. W. MacDonald, E. Kenchington, S. E. Campana, B. Sainte-Marie and M. Sacau, "Morphometry and growth of sea pen species from dense habitats in the Gulf of St. Lawrence, eastern Canada," Mar. Biol. Res., vol. 14(4), pp. 366-382, 2018.

[10] C. N. Rooper, P. Wilborn, P. Goddard, K. Williams, R. Towler and G. R. Hoff, "Validation of deep-sea coral and sponge distribution models in the Aleutian Islands, Alaska," ICES J. Mar. Sci., vol. 75(1), pp. 199-209, 2017.

[11] G. Chimienti, P. Maiorano and F. Mastrototaro, "Pennatula rubra facies in the Ionian Sea (Central Mediterranean)," Biol. Mar. Medit., vol. 22(1), pp. 76-80, 2015.

[12] G. Chimienti, L. Angeletti and F. Mastrototaro, "Withdrawal behaviour of the red sea pen Pennatula rubra (Cnidaria: Pennatulacea)," Eur. Zool. J., vol. 85(1), pp. 64-70, 2018.

[13] G. Chimienti, L. Angeletti, L. Rizzo, A. Tursi and F. Mastrototaro, "ROV vs trawling approaches in the study of benthic communities: the case of Pennatula rubra (Cnidaria: Cennatulacea)," J. Mar. Biol. Assoc. U.K., in press, 2018.

[14] J. A. Bertrand, L. Gil De Sola, C. Papaconstantinou, G. Relini and A. Souplet, "The general specifications of the MEDITS surveys," in Scientia Marina, vol. 66 (2), P. Abelló et al. Eds., 2002, pp. 9-17.

[15] L. Fiorentini, P.-Y. Dremière, I. Leonori, A. Sala and V. Palombo, "Efficiency of the bottom trawl used for the Mediterranean International Trawl Survey (MEDITS), ” Aquat. Living Resour., vol. 12(3), pp. 187-205, 1999.

[16] M. C. Fabri, L. Pedel, L. Beuck, F. Galgani, D. Hebbeln and A. Freiwald, "Megafauna of vulnerable marine ecosystems in French Mediterranean submarine canyons: spatial distribution and anthropogenic impacts,” Deep-Sea Res. Pt II, vol. 104, pp. 184-207, 2014.

[17] J. E. Cartes, C. Lo Iacono, V. Mamouridis, C. López-Pérez and P. Rodríguez, "Geomorphological, trophic and human influences on the bamboo coral Isidella elongata assemblages in the deep Mediterranean: to what extent does Isidella form habitat for fish and invertebrates?," Deep-Sea Res. Pt I, vol. 76, pp. 52-65, 2013.

[18] F. Mastrototaro, P. Maiorano, A. Vertino, D. Battista, A. Indennidate, A. Savini, A. Tursi and G. D’Onghia, "A facies of Kophobelemnon (Cnidaria, Octocorallia) from Santa Maria di Leuca coral province (Mediterranean Sea)," Mar. Ecol., vol 34, pp. 313-320, 2013.
[19] S. Petović, O. Marković, Z. Ikica, M. Đurović and A. Joksimović, "Effects of bottom trawling on the benthic assemblages in the south Adriatic Sea (Montenegro)," Acta Adriat., vol. 57(1), pp. 81-91, 2016.

[20] J. M. Pérès and J. Picard, "Nouveau manuel de bionomie benthique de la Méditerranée," Recueil des Travaux de la Station Marine d'Endoume, vol. 31, pp. 1-37, 1964.

[21] C. Carpine, "Ecologie de l'étage bathyal dans la Méditerranée occidentale," Bulletin de l'Institute Océanographique de Monaco, vol. 2, pp. 1-146, 1970.

[22] FAO (Food and Agriculture Organization), "International guidelines for the management of deep-sea fisheries in the High Seas," Rome, FAO, 2009.

[23] FAO (Food and Agriculture Organization), "Report of the Workshop on deep-sea species identification," Rome, FAO Fisheries and Aquaculture Report, no. 947, 2011.

[24] M. M. Otero, C. Numa, M. Bo, C. Orejas, J. Garrabou, C. Cerrano, P. Kružic', C. Antoniadou, R. Aguilar, S. Kipson, C. Linares, A. TerrónSigler, J. Brossard, D. Kersting, P. Casado-Amezúa, S. García, S. Goffredo, O. Ocaña, E. Caroselli, M. Maldonado, G. Bavestrello, R. Cattaneo-Vietti and B. Özalp, "Overview of the conservation status of Mediterranean anthozoans," IUCN, Málaga, 2017.

[25] P. W. Malecha and R. P. Stone, "Response of the sea whip Halipteris willemoesi to simulated trawl disturbance and its vulnerability to subsequent predation,” Mar. Ecol. Progr. Ser., vol. 388, pp. 197-206, 2009.

[26] E. Kenchington, F. J. Murillo, A. Cogswell and C. Lirette, "Development of encounter protocols and assessment of significant adverse impact by bottom trawling for sponge grounds and sea pen fields in the NAFO Regulatory Area, no. 6005," NAFO SCR Doc 11/75, vol 53, 2011.

[27] K. Fryganiotis, C. Antoniadou, C Chintiroglou and D. Vafidis, "Redescription of the Mediterranean endemic sea-pen Crassophyllum thessalonicae (Octocorallia: Pteroeididae)," Mar. Biodivers. Rec., vol. 4(e3), pp. 1-3, 2011.

[28] F. Mastrototaro, G. Chimienti, F. Capezzuto, R. Carlucci and G. Williams, "First record of Protoptilum carpenteri (Cnidaria: Octocorallia: Pennatulacea) in the Mediterranean Sea," Ital. J. Zool., vol. 82(1), pp. 61-68, 2015.

[29] S. Ambroso, A. Gori, C. Dominguez-Carrió, J. M. Gili, E. Berganzo, N. Teixidó, M. Greenacre and S. Rossi, "Spatial distribution patterns of the soft corals Alcyonium acaule and Alcyonium palmatum in coastal bottoms (Cap de Creus, northwestern Mediterranean Sea)," Mar. Biol., vol. 160, pp. 3059-3070, 2014.

[30] F. Mastrototaro, G. Chimienti, A. Matarrese, M. C. Gambi and A. Giangrande, "Growth and population dynamics of the non-indigenous species Branchiomma luctuosum Grube (Annelida, Sabellidae) in the Ionian Sea (Mediterranean Sea)," Mar. Ecol., vol. 36, pp. 517-529, 2015 . 